\title{
The South African Society of Psychiatrists is speaking up for good reasons
}

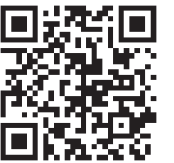

The South African Society of Psychiatrists (SASOP) is gearing up to shape mental health services in the country like never before. In this issue of the SAJP, Professor Bernard Janse van Rensburg explains SASOP's contributions to the National Mental Health Action Plan, ${ }^{[1]}$ following various recent strategic initiatives driven by the dictum, 'There can be no health without mental health, there can be no complete mental health without psychiatry'.

SASOP should play a pivotal role in shaping mental health services as part of the anticipated major changes in South Africa's health sectors, which include the planned implementation of national health insurance (NHI).

SASOP's growing capacity puts it in a progressively better position to shape South African mental health services in both the public and private sectors. SASOP celebrated its 60th anniversary during 2012: since its formation as the Society of Psychiatrists of South Africa (SPSA) in 1962, it has aimed to establish branches in all provinces of the country and, to quote Professor Gillis, 'has made an important contribution to the needs of psychiatric patients and the profession, acting as a pressure group for the mentally ill and holding regular conferences and meetings on academic topics and important issues of the day.[2] Psychiatry only developed a distinguished 'voice' as an organisation after SPSA/SASOP had separated from a specialist group of psychiatrists, neurologists and neurosurgeons in the then Medical Association of South Africa - a group that had been only 9 years old at the time. Since then, psychiatry has developed into a major discipline of medicine. SASOP has grown from a group of 70 psychiatrists in 1965 to today's 592, from a potential 730, members. We need to doff our caps to the early pioneers and veterans of our society, and build on their work.

SASOP is redefining its role and strategic vision in ways that are responsive to current changes in mental health services in both public and private sectors. The NHI plan will draw the public and private healthcare sectors closer, and is expected to revolutionise the healthcare industry by introducing an innovative system of healthcare financing with far-reaching consequences on the health of South Africans. ${ }^{[3]}$ The NHI 'is intended to bring about reform that will improve service delivery. It will promote equity and efficiency so as to ensure that all South Africans have access to affordable, quality healthcare services regardless of their socio-economic status. ${ }^{[3]}$

Given the well-documented connections between mental illness and poverty (as shown in work including that of our Western Cape colleagues, led by the late Professor Alan Flisher), the NHI has specific implications, including risks, for the discipline of psychiatry, and SASOP would be wise to have a critical influence on these effects. For example, psychiatrists have a role to play in preventative medicine, and I would argue that psychiatrists have a definite role to play in combating the so-called quadruple burden of disease in South Africa. We deal with non-communicable diseases, attend to persons emotionally scarred by interpersonal violence and accidents, and form part of the multidisciplinary treatment team for people living with HIV/AIDS and TB. Women's health and child welfare are increasingly recognised as important issues in mental healthcare.

SASOP should aim its influence at all four key interventions proposed to successfully implement the NHI, viz:

- a complete transformation of healthcare service provision and delivery

- the total overhaul of the entire healthcare system

- radical changes in administration and management

- the provision of a comprehensive package of care, underpinned by a re-engineered primary healthcare system.

The paradigm shift will be from a hospi-centric, curative and central approach to a district and municipal ward, communitybased, ambulant and preventative model of care. We need to define the psychiatrist's role within such a structure. At the same time psychiatrists should play a leading role in the training and research activities of central and specialist hospitals.

We need to take note of the objectives, of the NHI namely:

- to improve access to quality healthcare services

- to pool risks and funds to achieve equity and solidarity through the creation of a single fund

- to provide services on behalf of the entire population

- to strengthen the under-resourced and strained public sector so as to improve system performance.

The Honourable Minister of Health plans to achieve these objectives through a dual mechanism:

- pricing control in the private sector

- improving service quality at public hospitals, to which we, as public sector psychiatrists, can contribute.

To ensure quality in the public sector, we need to engage on a strategic and policy level, for example, when effective but costly medicine is earmarked for removal from various essential drugs lists (EDLs). It is incumbent on us to raise our voices as a collective. But this collective effort will require internal communication and debate with clear structures for engagement. In my opinion, active subgroups and special interest groups are the vehicle through which these debates and influence can and should take place.

Facing up to these and other current challenges to psychiatric services, we as a collective agreed to a set of 12 position statements at a SASOP/State Employed Special Interest Group (SESIG) workshop in Windhoek during 2012. ${ }^{[4]}$ How do we put our resolutions into action? We, as organised psychiatry, have access to various forums to influence policy. The heads of academic departments have regular meetings and have access to political decision makers. SASOP is fortunate that these colleagues are also SASOP members and contribute to the processes within the organisation. Similarly, the College of Psychiatry has an influence on the postgraduate training of psychiatrists. SASOP 
is also fortunate to interact with several NGOs involved in mental healthcare. In collaborating effectively with these various players, we expand our influence in the interest of the profession - not only by our participation, but also with vision and specific objectives as set out in the Windhoek position statements and engagement with the National Mental Health Action Plan. ${ }^{[1]}$

The SESIG leaders, particularly Dr Rob Allen and Professor Bernard Janse van Rensburg, are hard at work, not only at defining the form and essence of the public sector representation but also creating the idea and structure of a trade union function within the various public sector units. We would like see SESIG structures within all psychiatric unit and hospitals, with active SESIG committees in all subgroups, flowing ultimately to a nationally representative SESIG committee. We need to engage with the various political structures, both nationally and provincially, as a representative organisation on strategic issues. The aim is global solidarity with local emphasis.

In Position Statement 1, SASOP expressed its support for and involvement in drafting a national mental health policy. This process was begun with SASOP's leading participation in the first mental health summit during April 2012, which culminated in the Ekurhuleni Declaration. It continued with the Interim Ministerial Advisory committee on Mental Health, on which SASOP is represented by its past president Dr Ian Westmore and Professor Solomon Rataemane, who is also SASOP's International Relations representative. This committee is tasked with implementing the policy agreed upon in the Ekurhuleni declaration by focusing on the following six areas:

- the scope of state sector practice

- pertaining policies for state practice

- planning per region

- teaching and research

- accepted principles for care

- strategic mobilisation in view of set objectives

I have already alluded to SASOP's position that there can be no complete mental health without psychiatry. Psychiatrists' central role in strategic and operational planning is beyond question. But, in the game of politics, numbers count and we cannot ignore the role of the South African Medical Association (SAMA) in this regard. The SASOP Board met with representatives of SAMA on 9 February 2013. SAMA has various structures representing doctors in the public sector, including the Academic Doctors Association of South Africa (ADASA) and the Senior Hospital Doctors Association of South Africa (SEHDASA), but the board is of the opinion that these do not adequately represent our interests as medical specialists. Currently, SASOP is entitled to a seat on SAMA's National Council, but only through the Specialist Private Practice Committee (SPPC). The SASOP Board has considered 'borrowing' the seat on behalf of the public sector psychiatrists but remains committed to our collaboration with the South African Private Practioners Forum (SAPPF) as the representative organisation for private practice specialists.

Collaboration with SAMA remains essential for the formal trade union function that SAMA offers at the bargaining chamber. The board wants to encourage all SASOP members who are also SAMA members to stand for positions at the local SAMA branch level.

Adequate infrastructure and resource planning and allocation are essential for quality service delivery. The SASOP Board is concerned that the current norms are inadequate for this purpose and should be amended. SASOP members should become local advocates and activists in this regard, but having a strong, unified representative organisation will prevent the victimisation of individuals. SASOP as an organisation wants to step into the breach and raise our members' concerns.

The NHI envisages a defined package of care with 'as wide a range of services as possible. ${ }^{\left[{ }^{3]}\right.}$ Goods and services not covered by the NHI will include 'cosmetic surgery, expensive dental procedures for aesthetic purposes, expensive eye-care devices like trendy spectacles, medicine not included in the National Essential Drug List and diagnostic procedures outside of the approved guideline and protocols as advised by expert groups'. It is for us as an 'expert group' to determine which diagnostic, therapeutic interventions and medicines are essential for quality mental healthcare. Will gender reassignment surgery, for example, be considered 'cosmetic'? Should we have 'expensive' second generation antipsychotics on the EDL? If so, which? Indeed, we should speak up.

Although great strides have been made in turning the tide of the HIV pandemic, the HIV epidemic in South Africa remains a grave concern. It is a crucial element of the quadruple burden of disease. We psychiatrists are well aware of the neurocognitive and emotional impact of HIV infection, particularly in the vulnerable child and adolescent population already reported in 2001. A strong correlation between HIV infection and psychiatric disorders cannot be disputed. Cluver and Gardner investigated mental health outcomes for urban children parentally bereaved by AIDS in South Africa. According to their study, the number of such children is expected to rise from 1.1 million in 2003, to 3.1 million by 2010, peaking at 5.7 million South African children in 2015. They further commented that children orphaned by AIDS are exposed to multiple stressors which may compound and complicate the grieving process. They may have cared for and witnessed the death of parent/s with a debilitating illness, loss of bodily functions, and sometimes AIDS-related mental illness. Their study found that orphans were more likely to view themselves as having no good friends, to have marked concentration difficulties, to report frequent somatic symptoms and to have constant nightmares, while $73 \%$ of their sample scored above the cut-off symptom cluster for the diagnosis of post-traumatic stress disorder. It is vital that psychiatrists remain involved in the screening and treatment of children and adults living with HIV/Aids.

Another component of the quadruple burden of disease in South Africa remains that of substance abuse and addiction. These are complex bio-psycho-social conditions that are not only in the domain of health but also the purview of the departments of social development and education. SASOP recently created the Substance Use Disorders and Addictions Special Interest Group (SUDA-SIG) to promote the role of psychiatrists in the management of substance abuse and dependence. I, for one, would like to strengthen SUDASIG and make it a visible and active part of SASOP. The Honourable Minister of Health has indicated that he intends targeting the marketing practices of the alcohol industry in an effort the curb the detrimental effects of alcohol abuse.

Community-based services seems to be a key strategy in the NHI proposals. South African psychiatrists need to deliberate how and where we should fit into this model. In my opinion, the training of 
undergraduate students, interns and postgraduate students needs to reflect the changing philosophy in healthcare delivery to adequately prepare our students for the tasks they face.

SASOP is committed to the recovery and integration framework as treatment philosophy as discussed at the Windhoek meeting. I believe that we should have critical discussion regarding SASOP's relationship with NGOs and consumer groups. Perhaps turning to international experiences may be useful and I look forward to our future deliberations in this regard. SASOP's commitment to these relationships is based on its commitment to destigmatising mental illness within a service, but also a societal, context. It demonstrates a collaborative approach, working with our patients to decide on the best available treatment for each individual in a flexible, sincere, non-tokenistic, person-centred ethos.

Mental illness does not only affect the biological person but also influences the patient's interpersonal functioning. As such, it affects the patient's cultural and religious experiences, as acknowledged at the Windhoek meeting in Position Statement 9. We live in a heterogeneous society and SASOP publicly acknowledges that all faiths and belief systems should be respected and regarded as valuable to their adherents. This position necessitates critical reflection on our relationship with traditional health practitioners, following the promulgation of the Interim Traditional Health Practitioners Council of South Africa in January 2008 by the Traditional Health Practicioners Act of 2007. ${ }^{[5]}$ This Act recognizes diviners, herbalists, traditional birth attendants, traditional surgeons and tutors. It also aims to provide for a regulatory framework to ensure the efficacy, safety and quality of traditional healthcare services.

The Act defines traditional health practice as 'the performance of a function, activity, process or service based on traditional philosophy that includes the utilisation of traditional medicine or traditional practice and which has as its objective:

- the maintenance or restoration of physical or mental health or function

- the diagnosis, treatment, or prevention of a physical or mental illness

- the rehabilitation of a person to enable that person to resume normal functioning within the family or community or

- the physical or mental preparation of an individual for puberty, adulthood, pregnancy, childbirth or death. ${ }^{[5]}$ (my italics)

Traditional philosophy, according to the Act, means indigenous African techniques, principles, theories, ideologies, beliefs, opinions and customs and uses of traditional medicines communicated from ancestors to descendants or from generations to generations, with or without written documentation, whether supported by science or not:.$^{\left[{ }^{3}\right]}$ (my italics)

According to this Act, a person is disqualified from being appointed to the traditional health council if he or she is not a South African citizen; has been convicted of an offence carrying a prison sentence; has been found guilty of unprofessional conduct according to the Act; has been or is a member of the National Assembly, any provincial legislative body, the National Council of Provinces or any municipal council; is an employee or office bearer in any political party; or has been diagnosed with a mental illness, presumably in terms of the Mental Health Care Act. ${ }^{[5,6]}$ Psychiatry as a discipline clearly has overlapping interests with traditional health practitioners, more so because most of our patients will likely at some time consult a traditional health practitioner.
In my view, we require a critical discussion about SASOP's relationship with faith-based organisations and practices, including traditional practitioners in view of these regulations. It is up to us as the psychiatric community to shape the nature of our engagement.

The Health Professions Council of South Africa (HPCSA) recognises psychiatry as one of the five major clinical specialties, yet the training of interns in 'mental health' is delegated to family medicine for a four-week period. SASOP has long engaged with the HPCSA on this matter, arguing for a separate two- to four-week rotation, without much success. Care should be taken to ensure the availability of adequate supervision and the opportunity for overtime service within the psychiatry service, as these were the concerns raised by the HPCSA's internship training subcommittee.

SASOP is aware of the ongoing problems faced in providing forensic psychiatric services, as well as the need for better security at psychiatric hospitals and units, to adequately protect public sector mental healthcare practitioners from assault and injury while performing their clinical duties.

Position Statement 4 states that 'close collaboration and co-ordination should occur between the processes of establishing SASOP and national standard treatment guidelines, and the related decisions on EDLs for different levels. This will also require liaison with private sector practitioners. It can also be suggested that the authors of the SASOP treatment guidelines (who followed a formal peer review process) and the National Economic Development and Labour Council (NEDLAC) should form a standing committee and/ or other structures for ongoing liaison to explore procedural issues, as well as the current and ongoing revision of the current different lists of available drugs. If, however, finalising the national EDL would occur in the absence of such close collaboration and co-ordination in the EDL and STG processes, SASOP will have to express its grave concern, as psychiatry as a specialist clinical discipline will be prejudiced against, while the availability of evidence-based medications will be threatened, in particular within the public sector. ${ }^{[4]}$

SASOP has spoken up by recently publishing treatment guidelines, formulated by South African psychiatrists for the South African context. ${ }^{[7]}$ I am very proud and satisfied to note that the SASOP Standard Treatment Guidelines were launched at the Biological Psychiatry Congress 2013 at the Wild Coast Sun and published by the South African Journal of Psychiatry. That the compilation process took almost a decade reflects its complexity and the differing needs of the public and the private sector. We strive for 'evidence-based medicine', meaning the conscientious, explicit and judicious use of current best evidence in making decisions about the care of beneficiaries, whereby individual clinical experience is integrated with the best available external clinical evidence from systematic research. The benchmark of scientific knowledge is a head-to-head active component comparison in a random, double-blind design. This is not always available for drafting psychiatric treatment guidelines. In such cases, it can be argued that we need to rely on less rigorous evidence in the form of consensus by experts to guide us.

On 15 and 16 June 2006, such a consensus meeting was held by the then Clinical Peer Review committee of SASOP, involving not only psychiatrists but also interested general practitioners, clinical and counseling psychologists, occupational therapists, social workers, physiotherapists, psychiatric nurses, and the medical advisors of 


\section{Ary

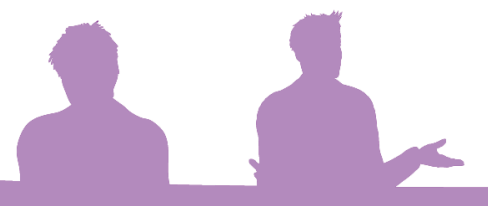 $A R$

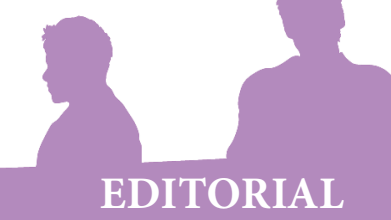

pharmaceutical companies, managed healthcare companies and medical schemes. The extensive consensus process was driven by Dr Eugene Allers, and the outcome was a set of draft guidelines that were published for further comment. In 2009 the SASOP Board of Directors established a Treatment Guideline Task Team under the guidance of Professor Robin Emsley, assisted by Professor Soraya Seedat, with the mandate to revisit the draft guidelines. They collated drafts and subjected them to blinded peer-review followed by a scientific editing process. There remains scope, however, to expand the guidelines from their current format into a working document, and we may need to create technical teams to implement them.

SASOP's Board of Directors was fortunate enough to meet with the Deputy Minister of Health on 22 February 2013, which I believe was a very successful and useful meeting. We presented the Deputy Minister with an overview of the structure and activities of SASOP and specifically discussed the following issues:

- the role of psychiatry in combating South Africa's quadruple burden of disease

- training of pre- and postgraduate students in the discipline of psychiatry in South Africa, as well as sub-specialisation

- access to mental healthcare in South Africa

- collaboration with government departments and NGOs

The Deputy Minister asked SASOP what can urgently be done to improve mental healthcare in South Africa (the so-called catalytic points), even before the mental health strategy has been completed and implemented. She referred to examples of human rights abuses and other problems in the Eastern Cape and KwaZulu-Natal. She urged SASOP to respond with media statements and communication to her office regarding problems that must be addressed. There should be zero tolerance for things that are unacceptable.

Awareness should be raised around these matters and the relationship between SASOP and the Department of Health should be based on shared values. If the department(s) or political leadership do not respond, legal action should even be considered. She noted that the national Department of Health has to take up its responsibility and will do everything to address problems and work constructively. SASOP's voice should be loud and clear to alert the department if necessary. Following our meeting with the Deputy Minister, I have no doubt that she considers SASOP the official representative organisation of psychiatry in South Africa. I for one am very excited about the possibility of real, regular engagement with the national department of health through the office of the Deputy Minister.

SASOP is speaking up for good reasons. Our membership should be joining the growing chorus that answers the question 'What does SASOP do for me?' with words and deeds, saying: 'SASOP creates an environment in which you can contribute to psychiatry in South Africa through its various forums and networks. Come, join and contribute as a professional citizen of South Africa.

We have come a long way as an organisation. We've managed to create structures and relationships through joint and successive efforts to serve the interests of organised psychiatry in South Africa. SASOP was born out of psychiatrists' need to have a voice. It would be bad enough if that voice were not heard to its growing capacity, but a sure travesty if it fell silent on psychiatry in South Africa.

\section{Dr Gerhard Grobler \\ President of SASOP \\ gpgrobler@sasop.co.za}

\section{S Afr J Psych 2013;19(4):201-204. DOI:10.7196/SAJP.511}

1. Janse van Rensburg ABR. Contributions from the South African Society of Psychiatrists (SASOP) to the National Mental Health Action Plan. South African Journal of Psychiatry 2013;19(4):205-212. [http://dx.doi.org/10.7196/SAJP.501]

2. Gillis L. The historical development of psychiatry in South Africa since 1652. South African Journal of Psychiatry 2012;18(3):73-82. [http://dx.doi.org/10.7196/SAJP.355]

3. South African Department of Health. National Health Insurance in South Africa Policy Paper. Pretoria: Government Printer, 2011.

4. Janse van Rensburg ABR, Allen R, Alonso-Betancourt O, et al. The South African Society of Psychiatrists (SASOP) and SASOP State Employed Special Interest Group (SESIG) position statements on psychiatric care in the public sector. South African Journal of Psychiatry 2012;18(3):133-148. [http://dx.doi.org/10.7196/SAJP.374]

5. South African Government. Traditional Health Practicioners Act 22 of 2007. Pretoria: Government Printers, 2007.

6. South African Government. Mental Health Care Act 17 of 2002. Pretoria: Government Printers, 2002.

7. Emsley R, Colin F, Flisher AJ, et al. The South African Society of Psychiatrists (SASOP) treatment guidelines for psychiatric disorders. South African Journal of Psychiatry 2013;19(3):128-199. [http://dx.doi.org/10.7196/SAJP.474] 